University of Nebraska - Lincoln

DigitalCommons@University of Nebraska - Lincoln

November 2007

\title{
Implementing Elements of Evidence-Based Practice Into Scientist-Practitioner Training at the University of Nebraska-Lincoln
}

\author{
David K. DiLillo \\ University of Nebraska-Lincoln, ddilillo@unl.edu \\ Dennis E. McChargue \\ University of Nebraska-Lincoln, dmcchargue2@unl.edu
}

Follow this and additional works at: https://digitalcommons.unl.edu/psychfacpub

Part of the Psychiatry and Psychology Commons

DiLillo, David K. and McChargue, Dennis E., "Implementing Elements of Evidence-Based Practice Into Scientist-Practitioner Training at the University of Nebraska-Lincoln" (2007). Faculty Publications, Department of Psychology. 255.

https://digitalcommons.unl.edu/psychfacpub/255

This Article is brought to you for free and open access by the Psychology, Department of at DigitalCommons@University of Nebraska - Lincoln. It has been accepted for inclusion in Faculty Publications, Department of Psychology by an authorized administrator of DigitalCommons@University of Nebraska - Lincoln. 
Published in Journal of Clinical Psychology, 63:7 (2007), pp. 671-685; DOI: 10.1002/jclp.20375 Published online in Wiley InterScience http://www.interscience.wiley.com Copyright (C 2007 Wiley Periodicals, Inc. Used by permission.

Portions of this article were presented at the Midwinter Meeting of the Council of University Directors of Clinical Psychology, Savannah, Georgia, January 2007. The authors would like to thank Sarah Evans for creating Figure 1.

Correspondence concerning this article should be addressed to: David DiLillo or Dennis McChargue, Department of Psychology, 238 Burnett Hall, University of Nebraska-Lincoln, Lincoln, NE 68588-0308; e-mail: ddilillo@unl.edu or dmcchargue2@unlnotes.unl.edu

\title{
Implementing Elements of Evidence-Based Practice Into Scientist-Practitioner Training at the University of Nebraska-Lincoln
}

\author{
David DiLillo and Dennis McChargue \\ University of Nebraska-Lincoln
}

\begin{abstract}
Evidence-based practice (EBP) has become the predominant model of training and is emerging as a common model of practice for many nonpsychology health care professions. Recognizing the relevance of EBP to psychology, the American Psychological Association (APA) developed and endorsed an official policy statement on EBP for the practice of professional psychology. There is now a pressing need to consider ways that EBP can inform scientist-practitioner training. The present article proposes clinical competencies associated with the practice of EBP, and describes initial efforts to implement elements of EBP into training at the University of Nebraska-Lincoln. These efforts have occurred in both the classroom and practicum training experiences, and are geared toward helping students become more effective users of the evidence base through their clinical work. Challenges to the implementation of EBP in clinical psychology training are discussed as well.
\end{abstract}

Keywords: evidence-based practice, training, clinical psychology, scientist-practitioner, American Psychological Association

The Clinical Psychology Training Program (CPTP) at the University of Nebraska-Lincoln has been continuously accredited since 1948, the year American Psychological Association (APA) accreditation began. Historically, the program's roots lay in the area of community clinical psychology and emphasized training in mental health service delivery, particularly in rural areas (Hargrove, 1991; Hargrove \& Howe, 1981; Howe, 1974). 
Although the program is still well integrated with the community, this focus has become more diffuse over the years. Further, with increased research productivity among faculty, the training pendulum has swung toward a balance between science and practice. As such, the integration of research and clinical work is viewed as an important feature of our program - one that is consistent with our Boulder model approach. Traditionally, this integration has been attempted in several ways (see Hope, Hansen, \& Cole, 1994). Starting in the mid-1990s, for example, we embraced the notion of empirically validated treatments (now called empirically supported treatments; Chambless \& Hollon, 1998) - an emphasis that continues in the program. Students are also exposed to the integration of science and practice through involvement in combined service delivery/research programs maintained by many of our faculty. These clinics specialize in treatment and research with specific problem areas (e.g., anxiety disorders, severe mental illness, child maltreatment) and offer students unique clinical training opportunities while simultaneously generating data that fuels productive research programs. Moreover, in addition to supervising these experiences, many faculty conduct clinical services within the clinics, and in doing so, provide students with models of science- practice integration.

Despite these ongoing efforts, there are clearly challenges to achieving the Boulder model's ideal of integrating science and practice in graduate training. One such challenge is avoiding the tendency to teach and train along related, but relatively disparate "tracks," which may discourage students from adopting a scientist-practitioner identity. Indeed, there is evidence that many practitioners (presumably trained using the Boulder model) do not utilize research to inform treatment (Nathan, 2000; Stricker, 2000). These and other concerns have led some to question the value and usefulness of the scientistpractitioner model altogether (Albee, 2000; Snyder \& Elliott, 2005). Although we remain committed to the Boulder model as a basis for training, concerted and sometimes creative efforts are needed if the two "halves" of our profession are to be integrated in a curriculum. As we hope to illustrate here - through a description of efforts underway in our own program - the incorporation of evidence-based practice (EBP) into graduate training represents one way to enhance this integration, in a manner that is complementary to scientist- practitioner training.

In addition to reinforcing the Boulder model, EBP is a useful training paradigm because it emphasizes a process approach to clinical work that can be applied in the context of the ever-evolving field. The rapidly changing science underlying psychological treatments means that the information students acquire in school quickly becomes obsolete. In response, the EBP approach is advantageous because it emphasizes that a process of active, lifelong learning that enables clinicians to keep up with changing treatment standards (Spring, in this issue). Students acquire the tools needed to access the most current knowledge, critically appraise that knowledge, and use it in clinical decision making.

Incorporating evidence-based principles into clinical training may also help prepare graduates to function more effectively within the current health care environment, where EBP is already being implemented as the dominant training and practice paradigm (Evidence-Based Medicine Working Group, 1992). In the broader health care context, EBP refers most generally to the use of scientific evidence to enhance individual patient care and improve accountability (Sox \& Woolf, 1993). These concepts are certainly not foreign to the practice of psychology and, in fact, are compatible with early notions of training in professional psychology (Shakow et al., 1947), as well as the more recent emphasis on empirically supported treatments (Chambless \& Hollon, 1998). The prevailing model of EBP adopted by the medical and health care communities was proposed by Sackett, Strauss, Richardson, Rosenberg, and Haynes (2000; and adapted by the Institute of Medi- 
cine $[\mathrm{IOM}], 2001)$ as "Evidence-based practice is the integration of the best research evidence with clinical expertise and patient values" (p. 147). Acknowledging the importance of EBP within the current health care environment - and recognizing the need for psychology to play a role in its ongoing development - the APA's Council of Representatives recently passed a formal policy statement regarding the evidence-based approach to the practice of professional psychology (APA, 2005). The definition of EBP adopted in this statement closely resembles the three-pronged model advanced by Sackett et al. (2000) and the IOM (2001).

Clearly, the EBP movement has increasing relevance for the practice of clinical psychology. Less clear, however, is how EBP can inform the training of doctoral psychologists. Although much has been written about EBP training in other fields, the majority of writings in psychology have been limited to basic conceptual issues (Walker \& London, this issue). Thus, for those seeking to integrate elements of EBP into training, there are few, if any, model programs to emulate. As a starting point, we suggest that EBP-oriented training should be geared at the broadest level toward training students in the competent use of what Barlow (2004) terms psychological treatments - that is, empirically supported interventions and techniques designed to alleviate psychopathology or to address the psychological aspects of medical conditions. This is not to ignore the role of socalled nonspecific factors. On the contrary, factors such as a strong therapeutic alliance can independently promote client change (Martin, Garske, \& Davis, 2000), as well as enhance the efficacy of empirically supported treatments (ESTs) for specific disorders (Ilardi \& Craighead, 1994; Spinhoven Giesen-Bloo, van Dyck, Kooiman, \& Arntz, 2007; Williams \& Chambless, 1990; Zuroff \& Blatt, 2006). Thus, nonspecific factors are essential components of psychotherapy training. However, the defining elements of psychological treatments (and EBP-oriented training) are competencies in theory-driven, empirically supported techniques used to treat particular psychological problems. After all, the demonstrated efficacy of these treatments places psychology on the firmest ground as a health care profession (Barlow, 2004). Our initial efforts in this regard have focused primarily on helping students become effective users of the evidence base through their clinical work. Of course, evidence-based practice also involves creating the evidence base through research (Spring et al., 2005) — and our students are quite active in that realm as well; however, because the majority of our recent efforts have focused on incorporating EBP into clinical training, that is the topic of this article.

\section{Theoretical Model of Evidence-Based Practice}

In integrating EBP into our training program, we have drawn heavily on the tripartite model initially proposed by Sackett et al. (2000) and later slightly adopted by the APA. Although readers may refer to other sources for more detailed discussion of this model (APA Presidential Task Force on Evidence-Based Practice, 2006; Norcross, Beutler, \& Levant, 2006), we provide a brief overview of the main components here.

The first component refers to utilization of the best available research evidence in treating clients. Thus, when making treatment decisions, clinicians must be guided by the strongest available empirical evidence. Research evidence is viewed hierarchically, with clinical anecdote and uncontrolled case studies at the bottom, and randomized controlled trials (RCTs) at the top, in the gold standard position (Muir Gray, 1997). Although evidence derived from RCTs is considered the strongest, even in the absence of an appropriate RCT, clinicians practicing EBP must avail themselves of the strongest research available evidence, regardless of where in the hierarchy the data lie. 
The second component of EBP encompasses various patient preferences and values. This involves considering the role of individual characteristics in treating clients. These characteristics include not only ethnic diversity, but also all kinds of values and individual differences that exist among clients. This component has been construed as involving the patient in treatment planning, which goes beyond basic informed consent at the outset of treatment, to include the involvement of clients in ongoing treatment decisions. This process involves informing clients about the chances that they will benefit from the evidencebased approach that is proposed by the provider, as well as the relative efficacy of any alternate empirically supported treatments (Barlow, 2004).

The final component is clinical expertise. Clinical expertise refers to the skills needed to assess, diagnose, and implement a treatment. In a training context, expertise can be viewed as helping students develop the skills to translate the evidence base, which is derived nomothetically, into an idiographic intervention that will work for a particular client, then monitoring patient progress and adjusting treatment as necessary within the bounds of sound clinical decision making.

\section{Operationalizing the Evidence-Based Practice Model}

In considering how EBP can inform training, an important question is: How can these rather abstract components be operationalized within a doctoral curriculum? In other words, is there certain knowledge, skills, or abilities that we want to impart to students in order to ensure they are gaining competence in the process of evidence-based practice? Figure 1 lists some of the competencies associated with each component of the EBP model. Although this list is certainly not exhaustive, we consider training in these competencies to be essential if students are to adopt an evidence-based approach to treatment.

Best available research evidence. In the realm of best available research evidence, a prerequisite is the need to adopt a scientific view of clinical psychology. This is a core tenet of evidence-based practice and it is our program philosophy. Thus, our students are introduced to the notion early in their training, through readings such as McFall's (1991) Manifesto for a Science of Clinical Psychology.

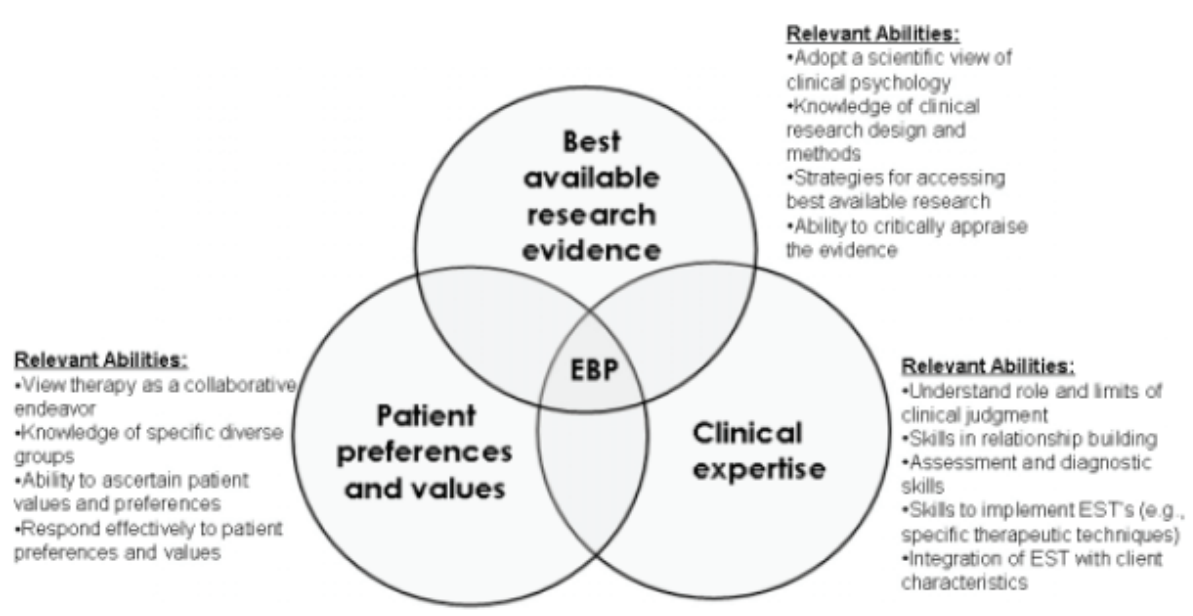

Figure 1. Consistencies associated with each component of the evidence-based practice model. 
Students also must acquire a thorough knowledge of clinical research design and methods. For example, they need to know about the hierarchy of research evidence, extending from individual case studies all the way through randomized controlled trials. They also need to understand the difference between efficacy and effectiveness studies, and how each of those is designed and conducted.

In addition, students need to learn strategies for accessing the best available research evidence in an efficient manner. This involves going beyond the traditional PsycInfo searches that are standard components of training. Rather, students should learn to use some of the newer and more comprehensive databases and search engines that specialize in synthesizing and cataloguing the ever-evolving evidence base (see Walker \& London, this issue).

Once they have accessed the best available research, students need to be able to evaluate that evidence critically. They must acquire knowledge that will allow them to critique the evidence related to specific treatments. This again highlights the need for training in the evaluation of intervention research.

Patient preference and values. Within this domain, students must view therapy as a collaborative endeavor - as an activity that is engaged in jointly between the therapist and the client, rather than something that is imposed upon the patient by the therapist.

Trainees must acquire knowledge of the specific diverse groups with whom they are working. For example, they need to know about the various ethnic and cultural groups that their clients come from and at the same time, take care not to overgeneralize or stereotype based on this knowledge.

Students also need the ability to ascertain patient values and preferences. Although psychologists are trained to assess various types of symptoms, we are much less accustomed to trying to understand the individual values and preferences that clients bring to therapy. How do therapists come to understand the subtle personal factors that can impact the therapeutic encounter? Unfortunately, these methods are not yet well understood, nor are the skills involved standard components of most training programs.

Once therapists have ascertained individual patient preferences and values, they must learn to respond effectively to them. If, for example, a therapist has selected a treatment that he or she believes is appropriate for a client's problem, yet the client has preferences or values that are in conflict with that treatment, the therapist must respond in a sensitive manner to the client values and preferences without compromising treatment efficacy.

Clinical expertise. Turning to the component of clinical expertise, one important competency is the development of basic therapeutic skills such as expressing accurate empathy, effective problem solving, and developing a strong working alliance. Because such skills can be facilitative of change in and of themselves, and are the basis for delivering psychological treatments (Fraser \& Solovey, 2007), they are essential in the process of engaging in evidence-based practice. These skills are not just natural abilities; they can be taught and learned in training programs, and are the basis from which specific treatments are delivered.

Students must acquire strong assessment and diagnostic skills. They need to be proficient in the use of common assessment instruments and approaches, including traditional (personality, cognitive) and behavioral assessment techniques. These skills are needed not only to arrive efficiently at an accurate diagnosis, but also to monitor outcomes throughout treatment.

An additional component of clinical expertise involves the skills needed to implement empirically supported treatments. Students need to acquire a range of specific thera- 
peutic techniques. For example, if an empirically supported treatment is exposure-based, calls for the use of cognitive restructuring, or includes a social skills training component, student therapists must become adept in the use of these various techniques. These skills are the building blocks of empirically supported treatments and are an essential aspect of clinical expertise.

One key aspect of clinical expertise involves the integration of empirically supported treatments with individual client characteristics. This ability highlights the role of clinical expertise in merging the other two components of the model. Specifically, clinical expertise is needed to blend the more nomothetically based use of best available research evidence with the more idiographic individual client characteristics, preferences, and values. If, for example, a therapist determines that a particular treatment may be warranted for a client, clinical expertise is required to determine how to best adapt that treatment for use with an individual client.

There is also a need for students to understand the role and limits of clinical judgment. This goes back to some of the classic writings by Meehl (1954) and others discussing the accuracy of clinical versus actuarial prediction. Therapists should be aware of the biases that they bring to their work, such as the tendency to make assumptions based on clients' race, gender, or social class (Garb, 1997). Students must also learn about the common tendency to place greater weight on personal beliefs and opinions than scientific evidence in making treatment decisions (Beutler, 2000).

\section{Efforts to Implement Evidence-Based Practice at the University of Nebraska-Lincoln}

Given these ideas about how to operationalize competencies associated with evidencebased practice, the next question was how and where to integrate these components into our training program. When our faculty considered this question, we realized that in many respects our training was already consistent with EBP. As noted, our students are trained in a model emphasizing the scientific bases of treatment. Accordingly, like many programs, our students receive strong training in experimental design and statistics, including training in clinical research design and methods. We also place a strong emphasis on sensitivity to issues of diversity as they emerge in the therapeutic context. Other core courses include psychopathology and an assessment series (e.g., personality and intelligence testing). Therefore, in many respects, our initial efforts involved highlighting these foci or "connecting the dots" to help students and ourselves gain a more coherent picture of the ways in which our training already mapped onto the EBP framework.

In other areas, however, we have made substantive changes to the curriculum to be more consistent with an evidence-based approach. What follows is a description of these changes. We believe that this shift may enhance the integration and utilization of an empirical approach to treatment. Our modifications have been concentrated in the areas of both coursework and practicum training. As described below, didactic changes focused on three courses that promoted the integration of the EBP model through structured didactic training of EBP as well as facilitating integration of material learned from other core courses. We also provide intensive clinical supervision (group plus live supervision) during students' initial exposure to clients, to allow for better integration of the EBP model. Finally, we encourage the dissemination of EBP in community agencies where practitioners and/or faculty are serving as clinical supervisors to our students and continually assist in the development of EBP competence via student participation within our "in house" specialty clinics where faculty members are actively conducting research. 


\section{Evidence-Based Practice Related Coursework ${ }^{1}$}

Proseminar in Clinical Psychology. All first-year students enroll in the 3-hour Proseminar in Clinical Psychology. The course objectives focus on a range of topics relevant for clinical psychology and the training of scientist-practitioners. There is a strong emphasis on EBP among the range of topics. First, students are presented an overview of EBP (e.g., APA, 2005; APA Presidential Task Force on Evidence-Based Practice, 2006). After the general model is presented, students then critically appraise each aspect of the model.

Topics consistent with EBP best research evidence cover a variety of readings on clinical research design (e.g., Kazdin, 2003) and clinical assessment (e.g., Garb, Lilienfeld, \& Fowler, 2005). Students are then exposed to readings examining research in clinical practice (e.g., Hawkins \& Hursh, 1992). The course also incorporates readings on a variety of topics related to EBP patient characteristics, culture, and preferences. General topic areas address the enhancement of effectiveness of interventions (e.g., Schwarz \& Baer, 1991; Stokes \& Osnes, 1989) and additional diversity issues (e.g., APA, 2003; Hansen, Zamboanga \& Sedlar, 2000).

Evidence-based practice clinical expertise topics are covered via readings and visual aids. Students discuss selected readings, such as Norcross and Hill (2004), and are also required to view videotapes of various approaches to therapy. Next, students discuss what they view as "expertise" within the tapes, and discuss commonalities and differences among approaches.

Such readings and visual aids are coupled with written assignments that promote integration of the EBP approach. Students directly observe one clinical session of an advanced graduate student within our departmental training clinic, the Psychological Consultation Center (PCC). They then write a case summary that addresses the following topic areas: assessment procedures or assessment-related issues; utility (or not) of the $D i$ agnostic and Statistical Manual of Mental Disorders, Fourth Edition (DSM-IV; American Psychiatric Association, 1994) in the identification of the assessment and treatment procedures; theoretical approach to treatment; the role of empirically supported treatments in the case; strategies to enhance generalization, maintenance, social validity, or treatment adherence; and consideration or influence of client characteristics or diversity issues.

Evidence-Based Clinical Interviewing. This 3-hour course represents the second didactic experience that integrates EBP and is taken during the second semester of the first year of training. The class is designed to train students in the use of basic therapeutic skills involved in interviewing as well as case conceptualization. The first section of the course focuses on developing therapeutic skills, such as establishing a therapeutic alliance, listening skills, accurate empathy, probing and summarizing, handling resistance, and identifying therapeutic red flags. Many of the skills are based on motivational interviewing principles (Miller \& Rollnick, 2002) coupled with some general therapeutic skills discussed by Morrison (1995). Motivational interviewing was chosen as the therapeutic skills training component for a variety of reasons. First, there is a standardized evaluation method of assessing competence (e.g., Bennett, Roberts, Vaughan, Gibbins, \& Rouse, 2006; Pierson et al., 2007). Second, many of the principles of motivational interviewing are common to basic therapeutic processes, such as specific listening skills, probing and summarizing skills, and skills to handle resistant clients. We believe such motivational

\footnotetext{
${ }^{1}$ Copies of course syllabi are available from the authors.
} 
interviewing skills strengthen the therapeutic alliance. Third, motivational interviewing has been shown to be therapeutically effective at changing behavior (e.g., Carroll et al., 2006). Fourth, although its origins are in substance abuse treatment, motivational interviewing has been applied to a variety of disorders (Arkowitz \& Westra, 2004; Barkhof et al., 2006).

The second section of this course addresses case conceptualizations and has a strong focus on integrating information within an EBP model. Our case conceptualization approach is roughly based on the methods of Persons and Davidson (2001). However, this approach was modified to reflect EBP, and emulate components required within our assessment and treatment plan report that is used within our training clinic. Qualitative EBP information required for our assessment and treatment plan includes how patient characteristics and problem list items are consistent with etiological literature. For example, students are asked to report the onset, prevalence, and prognosis of a specific disorder while taking into consideration individual difference variables such as gender, age, and ethnicity. In addition, questions are asked regarding whether the symptom profile is of the expected magnitude, quality, and duration for a particular client's characteristics. Based on this information, students construct two tentative working hypotheses and potential diagnoses with rule-outs.

Students in the class use videos of intakes conducted by advanced students to practice case conceptualization skills, while identifying areas in need of future assessment based on missing information. Students are asked to consider assessment needs that will help with differential diagnosis or, in cases where diagnosis is not feasible (such as couples therapy), they recommend assessments needed for a functional analysis. Students are required to report reliability and validity information regarding proposed assessment instruments, and to comment on whether the measures were standardized on populations that represent the patient characteristics. The second category focuses on measures that will be used to evaluate treatment effectiveness, including behavioral assessment techniques. Similar psychometric information is reported where applicable; however, for traditional assessment measures, students are also asked to identify research that would suggest specific cut-off scores or qualitative information that would indicate treatment success.

Another component of our case conceptualization is treatment recommendations. Students are taught techniques for searching EBP-related databases such as PubMed, PsychINFO, SUMsearch, Cochrane Reports, and Bandolier sites to identify relevant treatment outcome literature, with a particular focus on meta-analyses and systematic reviews, when available. Recommendations are driven by empirically supported treatments for specific diagnoses or treatments that have components that target symptoms of clinical interest. Further, recommendations are developed within a single case design format, particularly if recommended treatment deviates from the standardized protocol. Other information derived from research includes reports of the expected duration of treatment and projected effectiveness. Finally, students are required to present their conceptualizations and to write an assessment and treatment plan based on the conceptualization.

The third component of the class requires students to apply all the previous information and training from the course. Following didactic instruction and practice with structured diagnostic and semistructured interviewing techniques, students conduct one live intake interview in our clinic. Within this semistructured intake interview, students demonstrate competence in basic therapeutic skills acquired earlier in the class. Supervision is provided live by the course instructor, which allows for feedback as needed during the interview. 
Psychotherapy. The third course with a strong emphasis on EBP training is Psychotherapy, which is taught in the fall of the second year and coincides with students' first experience seeing clients in our training clinic (see the description of Clinical Intervention sequence below). The course is divided into thirds. The first section addresses, in some detail, topics such as the EST movement, efficacy and effectiveness research, treatment specificity versus common factors. Students also complete "refresher" readings on clinical research design and are reintroduced to the EBP framework as a means for accessing, evaluating, and applying the evidence base to clinical work. Significant attention is also paid to understanding the roles of ethnicity, gender, sexual orientation, and cultural factors in psychotherapy. The second third of the course focuses on training in the building block techniques of behavioral and cognitive behavioral therapy, including exposure procedures, cognitive restructuring, modeling, and social skills training. This is accomplished through readings, demonstrations (video and live), and role-playing. The final third of the class is devoted to in-depth student presentations of empirically supported treatments for particular disorders. Several aspects of these presentations are modeled after Leffingwell's (2006) Behavior Therapy Seminar Series workshops. For example, students code the quality of individual treatment outcome studies (with an emphasis on randomized controlled trials) along several dimensions as a means of evaluating the empirical support for the treatment they are presenting. Doing so requires them to apply their knowledge of research design to appraise the treatment literature critically. In keeping with the EBP notion of valuing client choice and values, students must explicitly address special issues for treating diverse client populations. They also create a client handout briefly describing the relevant disorder and recommended treatment, including the procedures involved, typical duration, and likelihood of treatment success in light of the empirical evidence. To foster the development of clinical expertise, the presentations also contain a role played demonstration of critical elements of each treatment, as well as a brief annotated bibliography of the best treatment literature (RCTs or meta-analyses) and most commonly used assessment instruments. The final exam for the class is an integrative exercise in which students choose from several client scenarios and describe in detail how they would diagnose, assess, and treat one of the cases presented. They must address the case using an evidence-based approach, including applying the best available evidence to the assessment and treatment plan, while considering the individual and tailoring the general principles found in the literature to the particular client.

\section{Evidence-Based Practice in Practicum Training}

Clinical Intervention sequence. Throughout students' second year of training they complete a two-semester clinical practicum called Clinical Intervention, which takes place in our training clinic. This intensive practicum is an opportunity for students to begin implementing an evidence-based approach to treatment. Therapists are placed within a treatment team of 3 to 5 students with a core faculty member. Caseloads start small and increase over the two-semester sequence. All sessions are observed by other team members as well as by the faculty supervisor who provides both live and group supervision. This mixed supervision format allows faculty to observe, evaluate, and intervene simultaneously, while stressing EBP principles. Live supervision also enables student therapists to benefit from the expertise of an experienced clinician who can "think aloud" about case conceptualization and treatment, as well as recognize problems and spot patterns that may be beyond the perceptions of beginning therapists. In this manner, Clinical Intervention sequence provides a unique forum for helping students develop clinical expertise. 
Specialty clinics and offsite practica. As noted, several faculty members maintain specialty clinics within the PCC, which focus on specific disorders (e.g., the Anxiety Disorder Specialty Clinic) or problem areas (e.g., the Family Interaction Skills Clinic). Faculty also conducts evidence-based treatment research within community settings. Students are exposed to such treatment research via their individual practicum placements and by maintaining an ongoing PCC caseload, while simultaneously accruing offsite practicum patient contact hours. Because offsite supervisors vary in their knowledge and utilization of EBP, the required ongoing in-house patient contact hours serve as our a useful means of evaluating and improving EBP competence over the student's remaining years.

Changes in clinic procedures. To assist in the integration of EBP practices across various aspects of the program, we have also made changes to the operating procedures of our training clinic, the PCC. Specifically, our assessment and treatment plans as well as our termination reports now reflect an EBP model. As describe above (i.e., EBP Clinical Interviewing Course), students' EBP case conceptualizations are used to formulate their assessment and treatment reports. The integration of case conceptualization, didactic training, and clinic reports resulted from our efforts to employ policies consistent with EBP. The format of termination reports has also been modified so that students evaluate their treatment outcomes and compare their treatment data with nomothetic findings. In addition to changing report formats, we are building a library of empirically supported treatment manuals within the PCC, and have established a committee consisting of University of Nebraska-Lincoln and external assessment experts who will provide guidance on the development and maintenance of our assessment resources.

\section{Evaluation of Outcomes}

Of course, if we are going to preach EBP as a program, we need to practice it too, by evaluating whether the efforts described above are resulting in new learning on the part of students. Toward that end, we have modified an exercise called clinical comprehensive exams ("clinical comps"), which takes place at the end of the second year, as the capstone experience of the Clinical Intervention course. Whereas clinical comps previously consisted solely of a videotaped demonstration of basic interviewing skills that was evaluated by a committee of three faculty members, recent modifications have added components to evaluate whether students are integrating EBP into their developing therapeutic approach. In addition to the demonstration of therapy skills, clinical comps now involve a description of case formulation and treatment planning within an EBP framework. The actual grading criteria for clinical comps can be found in Table 1. As can be seen, these criteria reflect the essential components of EBP.

\section{Challenges to Implementing Evidence-Based Practice}

As with any complex undertaking, there are a number of challenges to implementing EBP within a scientist-practitioner training program. One such challenge is that the EBP model is still evolving, especially in the field of psychology. As noted previously, approaches for training in EBP come primarily from medical schools; very little has been written about EBP training in psychology (Walker \& London, this issue). Although EBP is clearly establishing itself in our field, it remains unclear how some aspects are best translated into the training of clinical psychologists. The newness of the model also means that many faculty 
Table 1

Grading Criteria for Clinical Comprehensive Exams

Best Research Evidence

- Identify relevant empirical literature for the case

- Understand the relevant empirical literature and is able to apply it appropriately to the case.

Client Preferences and Values

- Identify client's values and individual characteristics that should impact assessment and treatment planning.

- Incorporate client values and individual characteristics into the conceptualization.

Clinical Expertise

- Demonstrate clinical expertise appropriate to this point in training to the case conceptualization, assessment, and treatment planning.

Development of an Evidence-Based Practice Treatment Plan

- Develop a case conceptualization that follows from the empirical literature, clinical judgment and client characteristics that can guide assessment, treatment planning, and implementation.

members are unfamiliar with the EBP framework and related concepts (e.g., the latest literature searching techniques). If EBP is to inform clinical training, faculty will need to acquaint themselves with the approach. One factor complicating progress in this area is confusion over terminology. For example, the term Evidence-Based Practice is now being used synonymously with Empirically Supported Treatments or to describe any treatment approach that draws in some way on evidence, broadly defined. Unless the field settles on consistent terminology, we fear that the EBP framework as delineated by the IOM (2001) and endorsed by the APA will be become diluted and less useful as a compliment to scientist-practitioner training.

A related issue is that faculty may not "buy in" to the notion of EBP. Although many would agree that the general components of the model are important, differences may arise over exactly how to implement EBP within a curriculum. Indeed, a number of concerns have been raised about EBP in psychology, including it origins in the medical model, the emphasis on RCTs as the gold standard of evidence, the relative importance that should be placed on each of the components of the model (e.g., which aspect contributes the most to treatment outcomes), and the model's applicability to diverse client populations (see Norcross et al., 2006 for a discussion of these and other controversies). Although faculty buyin has not been a problem in our program, these issues are significant and, at minimum, warrant open discussion. Even without total agreement regarding the implementation of EBP, such discourse may serve as a stimulus for improving clinical training.

There is also the question of whether and how to integrate outside supervisors into the EBP training model. Like many programs, outside psychologists sometimes supervise our students, particularly in their third and fourth years of training. As a program, we are considering how or even whether, to bring these outside supervisors into the EBP fold. For example, should programs offer community supervisors training or continuing education opportunities to better orient them to the model and, thus, to be more consistent with the training and supervision approach of the program? On the other hand, exposure to other perspectives later in training may be beneficial in helping students develop their own identities as practitioners.

Finally, there is the issue of how to measure the long-term outcomes associated with implementing EBP into our training model. We have made efforts to assess intermediate outcomes through clinical comps, but it remains unclear what effect the changes we 
are making have on long-term professional development. It is challenging to pinpoint the indicators of success, not to mention putting in place a means to assess progress toward those outcomes; however, in the future it will be essential to assess how efforts to integrate EBP into training actually affect the approach of graduates to practicing professional psychology.

\section{References}

Albee, G. W. (2000). The Boulder model's fatal flaw. American Psychologist, 55, 247-248.

American Psychiatric Association. (1994). Diagnostic and statistical manual of mental disorders (4th ed.). Washington, DC: American Psychiatric Association.

American Psychological Association. (2003). Guidelines on multicultural education, training, research, practice, and organizational change for psychologists. American Psychologist, 58, 377- 402 .

American Psychological Association. (2005). American Psychological Association policy statement on evidence-based practice in psychology. Retrieved February 21, 2007, from http:// www2.apa.org/practice/ebpstatement.pdf

American Psychological Association Presidential Task Force on Evidence-Based Practice. (2006). Evidence-based practice in psychology. American Psychologist, 61, 271-285.

Arkowitz, H., \& Westra, H. A. (2004). Integrating motivational interviewing and cognitive behavioral therapy in the treatment of depression and anxiety. Journal of Cognitive Psychotherapy, $18,337-350$.

Bandolier. (1994). Homepage. Retrieved February 19, 2007, from http://www.jr2.ox.ac.uk / bandolier/index.html

Barkhof, E., De Haan, L., Meijer, C. J., Fouwels, A. J., Keet, I. P. M., Hulstijn, K. P., et al. (2006). Motivational interviewing in psychotic disorders. Current Psychiatry Reviews, 2, 207-213.

Barlow, D. H. (2004). Psychological treatments. American Psychologist, 59, 869-878.

Bennett, G. A., Roberts, H. A., Vaughan, T. E., Gibbins, J. A., \& Rouse, L. (2006). Evaluating a method of assessing competence in motivational interviewing: A study using simulated patients in the United Kingdom. Addictive Behaviors, 32, 69-79.

Beutler, L. E. (2000). David and Goliath: When empirical and clinical standards of practice meet. American Psychologist, 55, 997-1007.

Carroll, K. M., Ball, S. A., Nich, C., Martino, S., Frankforter, T. L., Farentinos, C., et al. (2006). Motivational interviewing to improve treatment engagement and outcome in individuals seeking treatment for substance abuse: A multisite effectiveness study. Drug and Alcohol Dependence, 81, 301-312.

Chambless, D. L., \& Hollon, S. D. (1998). Defining empirically supported therapies. Journal of Consulting and Clinical Psychology, 66, 7-18.

Cochrane Library. (1999). Homepage. Retrieved February 19, 2007, from http://www3.interscience.wiley.com/cgi-bin/mrwhome/106568753/HOME

Evidence-Based Medicine Working Group. (1992). Evidence-based medicine. A new approach to teaching the practice of medicine. Journal of the American Medical Association, 268, $2420-2425$.

Fraser, J. S., \& Solovey, A. D. (2007). The therapeutic relationship. In J. S. Fraser \& A. D. Solovey (Eds.), Second-order change in psychotherapy: The golden thread that unifies effective treatments (pp. 65-86). Washington, DC: American Psychological Association.

Garb, H. N. (1997). Race bias, social class bias, and gender bias in clinical judgment. Clinical Psychology: Science and Practice, 4, 99-120. 
Garb, H. N., Lilienfeld, S. O., \& Fowler, K. A. (2005). Psychological assessment and clinical judgment. In J. E. Maddux \& B. A. Winstead (Eds.), Psychopathology: Foundations for a contemporary understanding (pp. 85-107). Mahwah, NJ: Erlbaum.

Hansen, D. J., Zamboanga, B. L., \& Sedlar, G. (2000). Cognitive-behavior therapy for ethnic minority adolescents: Broadening our perspectives. Cognitive and Behavioral Practice, 7, 54- 60.

Hargrove, D. S. (1991). Training Ph.D. psychologists for rural service: A report from Nebraska. Community Mental Health Journal, 27, 293-298.

Hargrove, D. S., \& Howe, H. E. (1981). Training in rural mental health delivery: A response to prioritized needs. Professional Psychology, 12, 722-731.

Hawkins, R. P., \& Hursh, D. E. (1992). Levels of research for clinical practice: It isn't as hard as you think. The West Virginia Journal of Psychological Research and Practice, 1, 61-71.

Hope, D. A., Hansen, D. J., \& Cole, J. K. (1994). The clinical psychology training program at the University of Nebraska-Lincoln. The Behavior Therapist, 17, 73-74.

Howe, H. E., Jr. (1974). An empirical description of a community-clinical training program. Professional Psychology, 5, 277-285.

Ilardi, S. S., \& Craighead, W. E. (1994). The role of nonspecific factors in cognitive-behavior therapy for depression. Clinical Psychology: Science and Practice, 1, 138-156.

Institute of Medicine. (2001). Crossing the quality chasm: A new health system for the 21 st century. Washington, DC: National Academies Press.

Kazdin, A. E. (2003). Research design in clinical psychology (4th ed.). Boston: Allyn and Bacon.

Leffingwell, T. R. (2006). The behavior therapy seminar series: A method for teaching evidencebased practice. The Behavior Therapist, 29, 77-80.

Martin, D. J., Garske, J. P., \& Davis, M. K. (2000). Relation of the therapeutic alliance with outcome and other variables: A meta-analytic review. Journal of Consulting and Clinical Psychology, 68, 438- 450 .

McFall, R. M. (1991). Manifesto for a science of clinical psychology. The Clinical Psychologist, 44, $75-88$.

Miller, W. R., \& Rollnick, S. (2002). Motivational interviewing: Preparing people for change (2nd ed.). New York: Guilford Press.

Morrison, J. (1995). The first interview; revised for DSM-IV. New York: Guilford Press.

Muir Gray, J. A. (1997). Evidence-based healthcare: How to make health policy and management decisions. London: Churchill Livingstone.

Nathan, P. E. (2000). The Boulder model: A dream deferred—or lost? American Psychologist, 55, 250-251.

Norcross, J. C., \& Hill, C. E. (2004). Compendium of empirically supported therapy relationship. In G. P. Koocher, J. C. Norcross, \& S. S. Hill (Eds.), Psychologists' desk reference (2nd ed., pp. 202-208). New York: Oxford University Press.

Norcross, J. C., Beutler, L. E., \& Levant, R. F. (2006). Evidence-based practices in mental health: Debate and dialogue on the fundamental questions. Washington, DC: American Psychological Association.

Persons, J. B., \& Davidson, J. (2001). Cognitive behavioral case formulation. In K. Dob (Ed.), Handbook of cognitive-behavioral therapies (pp. 86-110). New York: Guilford Press.

Pierson, H. M., Hayes, S. C., Gifford, E. V., Roget, N., Padilla, M., Bissett, R., et al. (2007). An examination of the motivational interviewing treatment integrity code. Journal of Substance Abuse Treatment, 32, 11-17.

Sackett, D. L., Straus, S. E., Richardson, W. S., Rosenberg, W., \& Haynes, R. B. (2000). Evidence based medicine: How to practice and teach EBM (2nd ed.). London: Churchill Livingstone. 
Schwartz, I. S., \& Baer, D. M. (1991). Social validity assessments: Is current practice state of the art? Journal of Applied Behavior Analysis, 24, 189-204.

Shakow, D., Hilgard, E. R., Kelly, E. L., Luckey, B., Sanford, R. N., \& Shaffer, L. F. (1947). Recommended graduate training program in clinical psychology. American Psychologist, 2, 539-558.

Snyder, C. R., \& Elliott, T. R. (2005). Twenty-first century graduate education in clinical psychology: A four-level matrix model. Journal of Clinical Psychology, 61, 1033-1054.

Sox, H. C., Jr., \& Woolf, S. H. (1993). Evidence-based practice guidelines from the U.S. Preventive Services Task Force. Journal of the American Medical Association, 169, 2678.

Spinhoven, P., Giesen-Bloo, J., van Dyck, R., Kooiman, K., \& Arntz, A. (2007). The therapeutic alliance in schema-focused therapy and transference-focused psychotherapy for borderline personality disorder. Journal of Consulting and Clinical Psychology, 75, 104-115.

Spring, B. (2007). Evidence-based practice in clinical psychology: What it is, why it matters, and what you need to know. Journal of Clinical Psychology, 63, 611- 631.

Spring, B., Pagoto, S., Kaufmann, P. G., Whitlock, E. P., Glasgow, R. E., Smith, T. W., et al. (2005). Invitation to a dialogue between researchers and clinicians about evidence-based behavioral medicine. Annals of Behavioral Medicine, 30, 125-137.

Stokes, T. F., \& Osnes, P. G. (1989). An operant pursuit of generalization. Behavior Therapy, 20, $337-355$.

Stricker, G. (2000). The scientist-practitioner model: Gandhi was right again. American Psychologist, 55, 253-254.

SUMSearch. (1998). Homepage. Retrieved February 19, 2007, from http://sumsearch.uthscsa.edu/

U.S. National Library of Medicine. (1971). Medline/PubMed homepage. Retrieved February 19, 2007, from http://www.ncbi.nlm.nih.gov/entrez/query.fcgi

Walker, B. B., \& London, S. (2007). Novel tools and resources for evidence-based practice in psychology. Journal of Clinical Psychology, 63, 633- 642.

Williams, K. E., \& Chambless, D. L. (1990). The relationship between therapist characteristics and outcome of in vivo exposure treatment for agoraphobia. Behavior Therapy, 21, 111-116.

Zuroff, D. C., \& Blatt, S. J. (2006). The therapeutic relationship in the brief treatment of depression: Contributions to clinical improvement and enhanced adaptive capacities. Journal of Consulting and Clinical Psychology, 47, 130-140. 